\title{
Beyond the Text: Digital Editions and Performance
}

\author{
BRETT D. HiRsch \\ University of Western Australia
}

JaNELLE JENSTAD
University of Victoria

$\sqrt{h}$

he alluring promises of digital editions blind many would-be editors to the sober realities of the undertaking. The heady days of the 1990sand the premature calls for the death of print at the hands of hypertextare over. Although computational tools may aid editors through full- or semi-automation of fundamental editorial processes, such as transcription, modernization, and textual collation, ${ }^{1}$ the digital medium introduces additional tasks to those involved in print, and complicates the tasks of producing and maintaining a critical edition. ${ }^{2}$

Digital editions are not for the faint of heart. As Coordinating Editor of the Digital Renaissance Editions (Hirsch) and Associate Coordinating Editor of the Internet Shakespeare Editions (Jenstad), we are intimately aware of the challenges of digital editions. In addition to traditional textual critical skills, the publisher of a digital edition requires technical expertise in programming and software development, textual encoding, interface design, methods of digitizing analogue materials, and digital content management. By contrast, a print edition can be left to fend for itself after publication - no further action on the publisher's part is required to ensure that a book remains readable, so long as copies survive in libraries and on bookshelves. Digital editions, on the other hand, require constant, hands-on, vigilant attention. Play editors for our series need not just full peer review of their work, ${ }^{3}$ but also guarantees of long-term preservation of their scholarly labor; we are both publisher and library. The digital editorial platform must adapt to changing technological specifications, redesign its interface periodically, plan for succession if the 
life of the project is to be longer than academic careers, check for "link rot" and "bit rot," and think about maintaining the functionality of digital tools that are built into the edition. Like a puppy, a digital edition is for life, not just for Christmas.

Given the additional technical complications, cultural and institutional pressures, funding issues, and administrative vigilance required to develop, maintain, and preserve such digital projects, why would any scholar bother producing them? Increased awareness of these attendant difficulties might explain why print remains the dominant medium for the publication of critical editions, and why so many digital projects founder, stagnate, or collapse altogether. ${ }^{4}$ Digital editors may regret their choice of medium and direct their energies elsewhere. However, the digital edition merits sober reassessment once the editor has been disabused of utopian digital visions and weighed the limitations of the medium against the opportunities. To be worthwhile, digital editions must offer something substantially different than their print counterparts. We suggest that the digital edition is particularly well suited to the needs of the performance edition, and, indeed, resolves some of the longstanding challenges for editors wishing to edit for performance. We both have a strong commitment to openaccess, open-source, online, and open-ended resources, which, we believe, offer the best return on the public's research investment. However, for the purposes of our argument about performance, we shall set aside the compelling claims we could make for digital editions on the grounds of knowledge mobilization, interoperability, transparency about encoding decisions, and universal access to anyone with an Internet connection. ${ }^{5}$

In this article, we employ Fair Em, the Miller's Daughter of Manchester (c.1590) as a case study to argue that, despite the associated theoretical and practical challenges, the affordances of the medium in relation to performance materials offer one of the most compelling reasons for the production of digital editions of early modern drama. We take Fair Em as our case study to make the point that the digital edition is particularly valuable for non-Shakespeare plays. For a Shakespeare play, not only have there been many editions over a long period of time, but the mammoth task of historical collation has also been done, and we still have a market that can support the publication of diverse, competing editions providing an array of editorial strategies. Such a market supports multiple performance editions of Shakespeare. For a non-Shakespearean play, there is usually a sparse editorial history and little to no performance history. Given the pressing need to establish a text and complete the traditional textual-critical tasks, non-canonical plays are unlikely to receive 
performance-based editorial treatment in print. The digital edition for such plays becomes particularly valuable because of its capacity to perform numerous editorial functions, incorporate future performance records, and avail itself of the fruits of new research and new performances that may even be generated by the edition itself.

\section{Editing as/for Performance}

"The introduction of new media," Lisa Gitelman aptly remarks, "is never entirely revolutionary" (6), and the digital edition is no exception. The history of producing machine-readable texts of Shakespeare's works alone dates back to at least the 1960s, when Trevor Howard-Hill, then preparing a series of old-spelling concordances for Oxford (1969-73), keyed all of the plays in ASCII format. Shakespeare editions on floppy disc and CD-ROM followed, but their fixed media formats and static content ensured that accessibility and utility were short-lived, with frequently extortionate prices further limiting their immediate impact. ${ }^{6}$ Such experiments in new media were important for developing the digital edition as we know it today, inasmuch as the history of trial and error suggests that simply rendering texts machine-readable is not enough. The Internet Shakespeare Editions platform began its life as a HyperCard stack on floppy disks, then an HTML hyperlinked "book" on CD-ROM, before it migrated to the Internet in $1996 .^{7}$ At its most basic, a digital edition consists of a curated text plus bibliographic and critical markup, and at least one set of instructions for processing and rendering the text in an interface. At its most complex, a digital edition may include multiple encoded texts, multiple standoff files that are keyed to those encoded texts, a wide array of multimedia resources, multiple ways of displaying the underlying files, and built-in tools for text analysis and visualization. Ideally, a digital edition will be open access (freely accessible to anyone with an Internet connection), open standard (as transparent about its digital practices as it is about its textual emendations), and open source (committed to making its code and markup visible).

The Internet Shakespeare Editions (ISE) and Digital Renaissance Editions (DRE), along with the Queen's Men Editions and the new Shakespeare au/in Québec project, publish complex digital editions running on what we call the "ISE platform." The ISE platform currently supports texts, site-wide resources that can be referenced from any edition (such as encyclopedias, companions, dictionaries, and glossaries), a performance database (including metadata about productions and digital 
artifacts from those productions), digital surrogates of early print and manuscript editions, an image database, text analysis tools, and static pages. An "edition" on this platform consists of documents prepared by editors (old-spelling and modern texts, collations, annotations, critical and textual introductions, and supplementary materials), aggregated with data from the multiple, ever-growing databases that are also supported by the platform. This practice of aggregating materials from across the site means that an edition may be richer tomorrow than it is today. The ISE platform is not the only model for a digital edition, ${ }^{8}$ but it was one of the earliest, remains one of most ambitious, and continues to evolve technologically.

Regardless of the platform, a digital edition has a number of practical characteristics that serve the performance edition particularly well. The digital edition is not subject to the material constraints of the print edition. Without word limits and page limits, we can include multiple texts, multiple types of annotations, and as many additional resources and supporting documents as we like; we do not have to choose between creating a textual-critical edition or a performance edition. The digital edition can accommodate old-spelling transcriptions of the early witnesses and multiple modern versions, with no concerns at all about shelf space. David Bevington's ISE Hamlet, for example, includes transcriptions of Q1, Q2, and F1; modernized texts of all three copy-texts; and an "Editor's Version" (an honest designation for the traditional conflated text). For Shakespeare's plays, this digital capacity is less crucial because the print market can support every possible editorial approach; for Hamlet, we have, in print, more than one modern Q1 text, editions based on Q2 or F, and no shortage of conflated texts, plus parallel text editions, variorum editions, performance editions, and directors' scripts. A performance edition of Hamlet has no need to establish a text or even to offer the traditional explanatory glosses. As Elizabeth Schafer notes, the Shakespeare in Production" series "bravely abandons all helpful notes on the meanings of words and replaces glosses with discussions of who did what when" (201). An edition of a non-Shakespearean play cannot afford to privilege one editorial activity over all others. "Because so much work has been and is being done on Shakespeare's text by other scholars," as Gary Taylor noted over twenty years ago, "producing a minimally competent edition of Shakespeare is much easier than producing a minimally competent edition of anyone else" (132). Editors of Shakespeare need identify only textual variants deemed "substantive" or "semi-substantive" for the purposes of historical collation; ${ }^{10}$ with shorter editorial histories to 
contend with, editors of non-Shakespearean plays are expected to produce historical collations of a detail and scope akin to those found in a variorum. While print editions allow Shakespeare editors to whittle down the historical collation even further, the same constraints of space often deny editors of non-Shakespearean plays the ability to meet the heightened expectations placed on them. Unlike Shakespeare editions, "judged by the standard of minimal textual competence," editions of non-Shakespearean plays "are judged by the highest standards of current textual theory and practice” (Taylor 132).

The digital edition can deliver multimedia materials in the same environment as the text. Video, audio, and image are all stored and delivered digitally. As Michael Best remarks, "one important difference between the electronic and the print text is, of course, the capacity of the electronic medium to go beyond text" ("Text" 269). Multimedia performance materials offer a unique opportunity for digital editors to move "beyond the text" and to produce dynamic performance editions and archives. As W. B. Worthen reminds us, "a specific performance cannot be extrapolated from text alone, much as a table cannot be extrapolated from a tree" (214). Thus performance editions are especially limited by the medium of print, however useful a resource they may be for researchers and theater historians. "While the range of resources for performance editions is excitingly unpredictable," in print "these multi-faceted resources inevitably suffer when being processed down into the service of staging commentary grounded in a text" (Schafer 208). Free from the static rigidity of the printed page, electronic editions can embed, extract, link, and juxtapose digitized performance materials in a variety of media formats. Without the same premium on space as in print, digital editions can provide commentary in addition to, and not instead of, the "multi-faceted resources" described by Schafer. For the same reason, digital editors can also afford to be agnostic about the selection of performance materials included in their editions: if we accept that every production is a statement of cultural value, electronic editions have an opportunity - if not an obligation-to "extend the range of productions surveyed beyond the usual suspects in any discussion of performance history" (Hirsch, "Kingdom" 577).

The open-endedness of the digital edition can be a curse ${ }^{11}$ in that knowing where to stop is a challenge, but it serves the open-ended nature of performance history well. The digital edition is not hermetically sealed. It invites interaction, correction, and extension. We can add new records and performance artifacts as future productions take place. Similarly, the digital edition is scalable- - built upon a structure that can be expanded in 
various directions and at different times - which is particularly useful if a play has no known performance history at all. One of the most significant advantages of the digital edition is that it can support multiple overlapping and/or discrete layers of annotation. A text can be carefully prepared by a textual editor who may or may not be interested in performance, either historical or modern. Others can annotate that text to produce a range of performance editions. Or, there may be no performance history to record until after the text is made available. The edition may even beget the productions that in turn make a performance edition feasible.

In instances where no performance history is recorded or what little is known is not readily accessible, digital tools offer the possibility virtually to reconstruct (or at least imagine) them. Joanne Tompkins and the team at Ortelia Interactive Spaces have built interactive, three-dimensional virtual Boar's Head and Rose playhouses, complete with scale models of props, audiences, and actor-driven avatars using motion capture technologies, relying on archaeological records and the work of theater historians to ensure they are as accurate as possible. To test long-standing assumptions about the relationships between actors, props, and theater space, Tompkins reconstructed a performance of Doctor Faustus at the Rose to experiment with various designs of a hell-mouth, a large property used to stage Faustus's climactic damnation (168-69). Jennifer Roberts-Smith and the team behind the Simulated Environment for Theatre (SET) have conducted similar experiments, producing a prototype edition of The True Tragedy of Richard the Third within a three-dimensional scale model of Queens' College Old Hall at Cambridge-one of the proposed early venues used by the Queen's Men on tour-alongside an annotated text of the play. Users are invited to "download and play" the edition, to alter the "blocking and text at will" and to test the team's findings in a process that "empower[s] users as creators" and "dissolve[s] the researcher-audience binary even more completely than performance can" (Roberts-Smith et al. 75, 78, 91).

More significantly, the digital edition has the capacity to support multiple understandings of "performance text" and speak to multiple constituencies. What is a performance text? A script that can be performed? A text that recreates a "thought production"12 and tries to recover something about how the play might have worked in early performance? One that records a particular performance? One that aggregates notes about significant past performances, as the Shakespeare in Production series does? One that permits dramaturgs and directors to edit the text to create a production? One that mobilizes the fruits of a performance-as-research 
project (such as the Queen's Men Project)? A digital edition does not have to be just one of these things. Finally, a digital edition can serve various users, both by its interactivity and by its capacity. We can build interfaces that give users control over the way that the underlying encoded files are rendered. At the most practical level, what actually appears on the screen can be controlled by the edition's users, who can turn collations on or off, or choose to privilege performance notes over other types of notes.

Beyond the practical reasons to consider a digital edition, we also see fundamental similarities between it and performance. Pascale Aebischer identifies the characteristics of performance as "ephemerality, spontaneity, productive interaction between spectators and actors, and the subjectivity of its reception" (17). Digital editions share many of these characteristics. We hope that the digital will not be ephemeral (good archiving and versioning practices are necessary), but it can be spontaneous in that the inter-actors can choose their own path through the edition, turn features on or off, choose to privilege one type of text or one type of annotation over others. Each viewing is a new dynamic instantiation that the viewer conjures up by sending a request to a server. While the viewer cannot generally write a new set of processing instructions, most digital editions now follow responsive design principles that recognize device types and sizes and change the appearance of the edition accordingly. The ISE platform, for example, recognizes whether users are on a mobile device or a larger screen. The digital environment can be even more productively interactive if digital commenting and annotating tools are integrated into the platform.

\section{Digitally Editing Fair Em}

As with many "non-canonical" plays from the period, the editorial history of Fair Em is markedly shorter than for its Shakespearean and "canonical" counterparts. The play is unlikely to receive fresh editorial treatment for many years after the completion of the Fair Em edition now in preparation for Digital Renaissance Editions by Hirsch and Kevin Quarmby. This forthcoming edition thus bears the twin burden of supplying the gaps left by a discontinuous editorial history and of anticipating the needs of the scholar and student further into the future than a Shakespeare edition would need to do. Not only will it give a complete textual history and apparatus, include digital surrogates and transcriptions of all the early texts, but it will also offer a fully modernized and critically annotated text. At the same time, this edition aims to be a performance 
edition, no mean feat given the complete absence of a performance history beyond the early modern period. This edition capitalizes upon the affordances of the digital edition - its capacity, iterativeness, and extensibility - to support and capture the results of performance-as-research exercises, thereby creating a performance history where none existed before.

\section{Textual-Critical Work}

This new edition will set the record straight on the early history of the text. Two early quartos are extant: the first undated but likely printed c.1592-93 (Q1), the second dated 1631 (Q2) and clearly set against a copy of Q1, which it follows page for page with only minor variations in typography and spelling. ${ }^{13}$ Only two copies of Q1 are recorded: a unique complete copy previously owned by Edmond Malone (1741-1812) and now in the Bodleian Library (Malone 208[5]), and a damaged partial copy previously owned by Henry Oxinden (1609-1670) and gifted to the Elham Parish Library, now part of the Canterbury Cathedral Library (Elham 386). Although twentieth-century scholars were aware that Oxinden possessed a copy of Fair Em-his manuscript miscellany, now in the Folger Shakespeare Library (V.b.110), records a list of plays in his collection-its whereabouts were unknown, and no previous editor consulted or collated it. ${ }^{14}$

Because the edition is digital and not subject to the same material constraints as a printed book, it can include all of the evidence that the editors themselves consulted in reconstructing the play's textual history. Digital surrogates of the early texts will be available for users to consult, including high-resolution photographs of the Malone and Oxinden copies of Q1, as well as facsimiles of Q2 from the Boston Public Library (Barton G.176.44 and G.176.45), the Beinecke Rare Book and Manuscript Library at Yale University (Elizabethan Club 201), and the Mary Couts Burnett Library at Texas Christian University (Lewis PR2860.A1). Transcriptions of Q1 and Q2 are available, allowing users of the edition to browse and compare facsimile images, as well as to read and search the old-spelling texts. These transcriptions will serve computer-aided textual analysis applications and data-mining exercises that have not yet been conceived.

The edition will offer a complete historical collation of editorial emendations. The most recent editor of Fair Em, Standish Henning, collates only six of the ten critical editions of the play that preceded his own, ${ }^{15} \mathrm{ad}-$ mitting "I have not collated [William Rufus] Chetwood's edition because he dealt irresponsibly with Q2 (his copy text) by adding lines, 'smoothing' 
the meter, and bowdlerizing" (Fair Em 98-99). Although this is certainly true-Chetwood's treatment of the text is questionable, as is his claim to have consulted a third quarto edition of 1619 that appears never to have existed-readers of Henning's otherwise exemplary edition are denied the opportunity to consider Chetwood's departures for what they are: unique eighteenth-century insights into the play. ${ }^{16} \mathrm{With}$ the exception of Henning's 1960 doctoral thesis, subsequently revised and published in 1980, and William Kozlenko's Disputed Plays of William Shakespeare (1974), which merely reprints the text of Henry Tyrrell's Doubtful Plays (1853), the electronic edition of Fair Em in preparation will include every edition of the play to date in its historical collation. This decision is in keeping with Sarah Neville's recent argument that digital editions have "the latency of a variorum, if not its explicit intent," and that the "variorum text serves as baseline against which the resources of a digital edition - with its unlimited capacity for accretive information-may be most comprehensively evaluated" ("Mediating" 134-35). As with other plays prepared for the Internet Shakespeare Editions and its sibling projects, users of the Fair Em edition will be able to select and display textual variants - in-line, color-coded, and marked with sigla - alongside the modern-spelling text prepared by the editors.

In some instances- such as the addition of speeches, or even entire scenes - the textual variations are so extensive as to render collation in print inefficient and inelegant. The so-called "fly scene" (3.2) in Titus Andronicus, printed in the Folio alone, is one such case: Jonathan Bate's Arden 3 edition of the play uses a distinct typeface to set the scene apart from the rest of his text, derived from Q1. Non-Shakespearean examples might also include the additional scenes in the B-text of Doctor Faustus, which, unless the edition offers separate A and B texts, are typically relegated to an appendix. Aside from Chetwood's extensive alterations, justified on the basis of a 1619 Quarto that may not have ever existed, comparable examples in the text of Fair Em include the numerous conjectural emendations proposed by Karl Elze in his series of Notes on Elizabethan Dramatists ("Notes" [1880] 6-20, 125-36; "Notes" [1884] 8-43, 191-93). One of these, first proposed in an earlier article ("Nachträgliche"), recommends systematic rearrangement of a succession of lines in the final scene of the play (39-41), corresponding to TLNs 1488-522.17 While this proposed reordering of the scene might be provided to readers as an appendix, the digital edition allows us as editors - and as readers - to have our cake and eat it too. By using a feature developed to allow readers to "flip" visually between different lineation of the texts of King Lear for 
Internet Shakespeare Editions, the edition of Fair Em will allow users to reorder the lines on-screen, "flipping" between the Q1 reading and Elze's conjectured emendation. ${ }^{18}$

The digital edition of Fair Em will be able to mobilize the latest computational methods to deal with the vexed question of the play's authorship, and make the data — and not simply the results—readily available to readers. No entry relating to Fair Em has been found in the Stationers' Register, and, while the title pages identify Lord Strange's Men as the acting company, neither Q1 nor Q2 provides any evidence of authorship. The scarcity of evidence has accommodated much speculation, and no fewer than seven authorial candidates have emerged: Robert Greene, William Shakespeare, Robert Wilson, Thomas Lodge, Anthony Munday, Edward Alleyn, and Thomas Kyd. ${ }^{19}$ Perhaps one of the more dubious of these attributions, Shakespeare's purported authorship of Fair Emprimarily derived from inclusion of the play in an early Sammelband titled "Shakespeare, Vol. 1.," originally in the Royal Library of Charles $\mathrm{I}^{20}$ - has sustained the majority of editorial interest in the play. Seven of the fourteen editions of Fair Em prepared after Q2 appear in collections of Shakespeare's apocryphal works. ${ }^{21}$

Finally, the digital medium is capacious enough to accommodate the most generous critical commentary and apparatus. Over the last century, one of the more striking changes in printed single-play editions of early modern drama has been the steady increase in the size of the introductory, contextual, and supplementary materials included. Consider the following examples from the Arden Shakespeare series: John Russell Brown's 1955 Arden2 edition of The Merchant of Venice, at 232 pages and 0.6 " in width on the shelf, is practically dwarfed by John Drakakis's 2010 Arden3 edition of the play, at 480 pages and one inch in width, whereas David Bevington's 2015 revision of his original 1998 Arden 3 edition of Troilus and Cressida adds an additional 48 pages and 0.6 inches in width. The same is true for non-Shakespearean plays: Clara Calvo and Jesús Tronch's 2013 Arden Early Modern Drama edition of The Spanish Tragedy boasts 392 pages, whereas Philip Edwards's 1959 Revels Plays edition of the play ran to only 223 pages. This expansion reflects a growing desire on the part of readers for greater contextual information, and a willingness-if not eagerness - on the part of editors to provide it. There are limits to this literal widening of the canon, however, inasmuch as editors are constrained by the conventions of print and the restrictions imposed by publishers. As Neville remarks, "the digital text is unhindered by the necessity of a page's visual correspondence between text and note." While 
editors of printed editions "fret over the minor-font footnotes that can extend to crowd out the body of the text proper and upend the traditional hierarchies of the mise-en-page," editors of digital editions enjoy a greater degree of freedom. The introductory, contextual, and supplementary materials "appended to the digital text can be as long and detailed as an editor desires, since the affordances of the editions' various technologies" allows for them "to remain hidden until they are specifically called into being by a reader-user ready to make use of them" ("Mediating" 135). ${ }^{22}$ In addition to the conventional critical and textual introductions, the digital edition of Fair Em will include extensive annotations ranging in levels of detail from gloss to essay-length discussion, as well as generous supplementary materials, such as textual sources, analogues, and adaptations of the play.

\section{Building the Performance Edition}

As outlined above, the rich contextual and analytical materials, the full range of digital surrogates, and the integration of computational tools and datasets supported by the digital platform may be sufficient to distinguish an electronic edition of Fair Em from its predecessors in print. However, Hirsch and Quarmby are committed to using the full capacities of the digital medium to supply a performance edition. The challenge for the editors of Fair Em, as for digital editors of most non-Shakespearean plays, is the paucity or absence of a documented performance history. How are the editors to build a performance edition for such a play? The options available to the editors were to embed virtual reconstructions (a strategy unavailable to editors in print) or to commission and record performances of key scenes and performance-as-research exercises. Given Quarmby's expertise as a theater practitioner, and the generous cooperation of theater companies, it became possible to explore a third option: creating a new, modern performance history and leaving open the option to capture future productions.

The virtual reconstruction option for Fair Em is complicated by the lack of evidence identifying a specific early modern performance space. According to the title-pages of both Q1 and Q2, Fair Em was "sundry times" publicly acted in London by Strange's Men. There is no entry for Fair Em in Philip Henslowe's records of performances by Strange's Men at the Rose in 1592-93, which, along with several topical allusions in the play, suggests an earlier date for performances in London and on tour, c.1589-91. ${ }^{23}$ While it is possible to experiment with various staging options for Fair Em using virtual reconstructions of historical performance 
venues (such as the Rose generated with Ortelia, SET, or similar software applications), the play perhaps lacks the sorts of site-specific performance cruxes to justify the effort and expense involved to create the models, motion-capture the actor-avatars (in the case of Ortelia), or program the blocking in relation to the text (in the case of SET). That said, the Creative Commons licenses on the texts prepared for the Fair Em edition will allow readers to remix, tweak, and build upon them in any way-including importing them into virtual environments such as SET-provided the source is acknowledged and the use is noncommercial.

Another option for the digital editor is to commission and record performances of scenes and sequences, following the example of Richard Brome Online. The editors of Richard Brome Online employed professional actors drawn from the alumni lists of the Royal Shakespeare Company and Shakespeare's Globe to explore crucial scenes in a series of workshops, all of which were recorded. "Besides conventional explanatory glosses and annotations," these recording--over thirty hours of footage divided into some 640 clips-form an additional layer of annotation to the texts of the edition, "illustrating interpretations of the passage (often played in contrasting ways), which in turn augments annotational discussions of staging" (Cave, Lowe, and Woolland 218). In their function as annotations, exploring the dynamics and theatrical possibilities of the text, such video clips of performance are immeasurably valuable to both editor and reader. They also serve as important reminders that stage business is often rendered invisible in the text. Silent characters are a pertinent example: since "the dramaturgical strategy is wholly visual" and "no conventional means of designating on the page such a character's continuing presence within a scene" exists, "there is a risk the character will escape the reader's attention to the text" (Cave, Lowe, and Woolland 229). As the editors of Richard Brome Online discovered, workshops "demonstrated how powerful a silent character can be and the complex repercussions this can have on the overall tone of a sequence" (Cave, Lowe, and Woolland 229).

Inspired by this successful feature of Richard Brome Online, Quarmby will workshop short sequences and performance cruxes with student actors at Emory University, to be recorded and incorporated into the Fair $E m$ edition as an added layer of performance annotation. For example, one such performance crux in the play occurs when the titular Em fends off the unwanted advances of Mountney. Q1 gives:

468 He turnes to Em, E' offers to take her by the hand, Es shee goes from him.

469 Faire mistres, since my fortune sorts so well: 
470 Heare you a word. What meaneth this?

471 Nay stay faire $E m$.

$472 \mathrm{Em}$. I am going homewards, sir.

All previous editors of the play have left this passage unaltered. For the modern text of the digital edition, we decided to split the stage direction at TLN 468 to provide a better sense of flow in the action:

He turns to Em.

[MOUNTNEY] Fair mistress, since my fortune sorts so well,

Hear you a word.

$[\mathrm{He}]$ offers to take her by the hand, and she goes from him.

What meaneth this?

Nay, stay, fair Em.

EM. I am going homewards, sir.

We may revisit this decision after the workshops, since the flow in action may not require any editorial intervention. Another element of this exchange to play out in a workshop is the second half of TLN 470. Q1 assigns the entire line to Mountney, but it makes as much sense to reassign the second half to Em. "What meaneth this?" works equally well as an expression of Mountney's surprise at being rebuffed (the Q1 reading) or as a reasonable response by Em to an unprovoked physical advance (the conjectural emendation). The one reading renders Em more aloof and evasive, the other more bold and assertive. The reassigned line can also be played another way: Em is soon to begin feigning deafness in an effort to deter Mountney's courting, so "What meaneth this?" may be interpreted as a literal response to "Hear you a word," allowing the actor playing Em to begin the ruse earlier.

A similar option for digital editors is to follow the example of Performing the Queen's Men, the performance arm of the Shakespeare and the Queen's Men project: commission and record the staging of a play in its entirety, from which to generate an additional layer of performance commentary to accompany the texts published by Queen's Men Editions. In 2006, the project staged three plays associated with Queen Elizabeth's Men-The Famous Victories of Henry the Fifth, Friar Bacon and Friar Bungay, and King Leir-to conduct performance-as-research investigations into the Elizabethan rehearsal process, doubling, stage traffic, the performance of gender using an all-male cast, props, and other elements of dramaturgy. ${ }^{24}$ However, if a digital edition includes only a single production, whether it is a virtual reconstruction or recorded live 
performance, there is a danger of promoting it as definitive. This danger is precisely why Richard Brome Online engaged actors to workshop the rich potentiality of selected sequences rather than produce finished productions of each play in its entirety. The intention to experiment with early performance practices goes some way to mitigate the single performances documented by Performing the Queen's Men, but even these may have been usefully supplemented with workshop footage.

The first modern revival of Fair Em was directed by Phil Willmott for The Steam Industry at the Union Theatre, Southwark, from 8 January to 9 February 2013. Advertised as being "by" or "sometime attributed to" Shakespeare, Willmott's production engaged in what Kirwan has aptly termed the "appropriation of authorial capital" (Shakespeare 199). This emphasis on Fair Em's apocryphal status not only affected the expectations of the audience and reviewers, but also may have justified Willmott's decision to interpolate lines from Henry the Sixth, Part Three into his adapted script. Folk music and song were also incorporated into the adaptation, performed by "Green Willow," characterized in Neville's review as "an onstage quintet that served as the play's doo-wop musical accompaniment and de facto chorus" (537).

Two North American productions of Fair Em followed. In November 2013, the Oxford Ensemble of Shakespearean Artists - a group of undergraduate students who mount a Shakespeare production each fallstaged two performances of the play at the Tarbutton Theater in Oxford College, Emory University. Although it bears many of the hallmarks of an entirely student-run production, such as unfamiliarity with aspects of Elizabethan prosody, the limited budget necessitated some remarkable inventiveness with the available resources: for example, cock-horses ridden by the noblemen did double duty as swords. Tom DuMoniter directed a more polished production at the Blackfriars Playhouse in July 2014. As part of the American Shakespeare Center's Theater Camp, the production featured a gender-blind cast of students aged between 13 and 18, all of whom gave impressive performances.

Thanks to the incredible generosity of those involved in The Steam Industry, Oxford Ensemble of Shakespearean Artists, and American Shakespeare Center productions, the digital edition of Fair Em is in the enviable position of being able to offer multiple video recordings of the entire play in performance, as well as a variety of digitized archival materials, photographs, workshop clips, and interviews. Engagement with multiple performances allows the editorial commentary to be comparative in nature - to focus on different staging, casting, characterization, move- 
ment, and costuming, as well as cuts and extra-textual insertions-and to avoid privileging any one production over another. Doing so in the context of a digital edition allows the comparisons themselves to move "beyond the text" and be presented in/with relevant media: for example, demonstrating vocal characterizations between productions aurally using embedded audio and video clips, illustrating movement and blocking with still and moving images of performance, juxtaposing allusions to-as well as sources and analogues in-non-textual media, and so on.

\section{Coda}

In 1611, Randle Cotgrave glossed the French ranimer as "To reanimate, reincourage, reuine, put into heart; infuse new vigor, life, or spirit into" (3U4r). Over the course of some 400 years since Cotgrave published his Dictionarie, the majority of English Renaissance plays have languished undervalued, underedited, and underperformed. For a Shakespeare play, there will always be a market for another edition, taking a different editorial stance, incorporating the latest criticism, and commenting on the most recent productions. For the noncanonical, non-Shakespearean play, the digital edition might be the only critical edition to appear in a generation or at all. The more it can achieve, the better the chances for the play to be taught, performed, and studied..$^{25}$ Moreover, the capacity of digital editions to go "beyond the text," to enable forms of user interaction, and to support the ongoing collection and integration of multimedia performance resources - in effect, to become accretive, responsive archives and dynamic performance editions-perhaps offers the only viable opportunity to truly reanimate these neglected playbooks.

\section{Notes}

${ }^{1}$ Representative examples include the optical character recognition tools developed by the Early Modern OCR Project (eMOP), VARD2 for standardizing spelling, and Juxta for collating textual variants.

${ }^{2}$ On these challenges, see Alan Galey ("Mechanick Exercises"), Eugene Giddens ("Digital Revolutions"), and Brett D. Hirsch ("The Kingdom").

${ }^{3}$ The MLA's recently updated statement on electronic publication prescribes the same metrics for digital and electronic editions: "departments evaluating scholarly publications should judge journals, monographs, or other substantial scholarly works according to the same criteria, whether they are published in digital or print formats."

${ }^{4}$ For an engaging discussion of these issues, see Robin Camille Davis. 
${ }^{5}$ For those interested in pursuing those justifications, Gabriel Bodard and Juan Garcés give a rationale for open-source editions that publish their code and markup.

${ }^{6}$ For more detailed discussion of the history of electronic editions than is possible here, see Michael Best ("Shakespeare”), Galey (The Shakespearean Archive), and Hirsch and Hugh Craig.

${ }^{7}$ See Best and Jenstad ("The ISE").

${ }^{8}$ For discussion of other models, real and imagined, see Francis Connor, Eugene Giddens, and Hirsch (“The Kingdom”).

${ }^{9}$ Published by Cambridge University Press, under the general editorship of J. S. Bratton and Julie Hankey. According to the jacket blurb and press catalogue, the individual play editors add to the New Cambridge text "detailed, line-by-line evidence for the overview presented in the introduction."

${ }^{10} \mathrm{On}$ the debate of what can and should be included in historical collation in editions of Shakespeare, see Fredson Bowers and Paul Werstine.

${ }^{11}$ See, for example, the essays in the "Done" special cluster of Digital Humanities Quarterly 3.2 (2009), edited by Matthew G. Kirschenbaum, all of which deal with the tension between the demands and expectations of funding agencies, publishers, and other institutions for "finality" and what Julia Flanders has aptly described as the culture of the "perpetual prototype." See also Pierazzo (“A Rationale" 463).

${ }^{12}$ We borrow the term from M. M. Mahood (9).

${ }^{13} \mathrm{On}$ the early printing of the play, see Greg ( $\left.\mathrm{v}-\mathrm{x}\right)$ and Henning (Fair Em 1-27), the latter supplying detailed compositorial analysis.

${ }^{14} \mathrm{~A}$ transcription of Oxinden's list is available in Giles E. Dawson and the Lost Plays Database. Use of the Oxinden copy for collation is limited, since only a few leaves survive. The Malone copy collates $4^{\circ}: \mathrm{A}-\mathrm{F}^{4}$, whereas the Oxinden copy collates $4^{\circ}$ : A-C $(\mathrm{C} 2, \mathrm{C} 3$, missing; B4 partial).

${ }^{15}$ That is, Tyrrell (1853), Delius (1874), Simpson (1878), Warnke and Proescholdt (1883), Brooke (1908) and Greg (1927), excluding Chetwood (1750), Hopkinson (1895), Barzak (1959), and Kershaw (1972). Henning (1980) mentions Barzak's edition only as it relates to the issue of authorship.

${ }^{16}$ For a defence of early performance editions, see Laurie E. Osborne.

${ }^{17}$ All references to Fair Em are from the modern text in Hirsch and Quarmby's edition for Digital Renaissance Editions, cited parenthetically by ThroughLine Number (TLN).

${ }^{18}$ This feature is described in Best ("The Linking”).

${ }^{19}$ For an overview of the authorship debate, see the entry for the play in Anne Lancashire and Jill Levenson. See Brian Vickers for the attribution of Fair $E m$ - as well as several other early anonymous plays - to Kyd, and MacDonald P. Jackson for a persuasive critique.

${ }^{20}$ For a detailed discussion of this early collection, see Peter Kirwan ("The First”). 
${ }^{21}$ Namely, the editions of Tyrrell (1853), Delius (1874), Simpson (1878), Warnke and Proescholdt (1883), Hopkinson (1895), Brooke (1908), and Kozlenko (1974). The remaining editions include Chetwood (1750), Farmer (1911; a photo-facsimile), Greg (1927), Barzak (1959), Henning (1960, 1980), and Kershaw (1972).

${ }^{22}$ See also Best ("Standing" 31-35) and Galey ("Signal" 57).

${ }^{23}$ See Lawrence Manley and Sally-Beth MacLean (104-5), Greg (Fair Em vii), and Henning (Fair Em 80-81).

${ }^{24}$ Further performances for the project include The True Tragedy of Richard the Third in 2007, Clyomon and Clamydes in 2009, and The Three Ladies of London in 2015. At time of writing, materials from these performances are not yet incorporated into the Performing the Queen's Men site.

${ }^{25}$ See Hirsch ("The Kingdom") and Roberts-Smith et al.

\section{Works Cited}

Aebischer, Pascale. Shakespeare's Violated Bodies: Stage and Screen Performance. Cambridge: Cambridge UP, 2004. Print.

Apollon, Daniel, Claire Bélisle, and Philippe Régnier, eds. Digital Critical Editions. Urbana: U of Illinois P, 2014. Print.

Barzak, Robert William, ed. Faire Em: A Critical Edition, with an Introduction on the Authorship of the Play. Diss. U of Illinois, 1959. Print.

Bate, Jonathan, ed. Titus Andronicus. London: Arden Shakespeare, 1998. Print. Best, Michael. "Shakespeare on the Internet and in Digital Media." The Edinburgh Companion to Shakespeare and the Arts. Ed. Mark Thornton Burnett, Adrian Streete, and Ramona Wray. Edinburgh: Edinburgh UP, 2011. 55876. Print.

- "The Text of Performance and the Performance of Text in the Electronic Edition." Computers and the Humanities 36 (2002): 269-82. Print.

— . "Standing in Rich Place: Electrifying the Multiple-Text Edition, or, Every Text is Multiple.” College Literature 36.1 (2009): 26-36. Print.

—_. "The Linking of the Kingdoms: Creating a Digital Edition of King Lears." Early Modern Literary Studies. Forthcoming.

Best, Michael and Janelle Jenstad. "The ISE: A Brief History." Internet Shakespeare Editions. Internet Shakespeare Editions, 2013. Web. 20 Dec. 2015.

Bevington, David, ed. Hamlet. Internet Shakespeare Editions. Internet Shakespeare Editions, 2014-. Web. 15 Dec. 2015.

— ed. Troilus and Cressida. London: Arden Shakespeare, 1998. Print.

, ed. Troilus and Cressida. Rev. ed. London: Bloomsbury Arden Shakespeare, 2015. Print.

Bodard, Gabriel, and Juan Garcés. "Open Source Critical Editions: A Rationale." Text Editing, Print, and the Digital World. Ed. Marilyn Deegan and Kathryn Sutherland. Farnham: Ashgate, 2009. 83-98. Print. 
Bowers, Fredson. "The Historical Collation in an Old-Spelling Shakespeare Edition: Another View." Studies in Bibliography 35 (1982): 234-58. Print.

Brooke, C. F. Tucker, ed. The Shakespeare Apocrypha. Oxford: Clarendon, 1908. Print.

Brown, John Russell, ed. The Merchant of Venice. London: Methuen, 1955. Print. Calvo, Clara, and Jesús Tronch, ed. The Spanish Tragedy. London: Bloomsbury Arden Shakespeare, 2013. Print.

Cave, Richard, Eleanor Lowe, and Brian Woolland. "Actors and Editors: A Feature of the Edition Richard Brome Online." Editing, Performance, Texts: New Practices in Medieval and Early Modern English Drama. Ed. Jacqueline Jenkins and Julie Sanders. New York: Palgrave, 2014. 218-37. Print.

Chetwood, W. R., ed. A Select Collection of Old Plays. Dublin: W. R. Chetwood, 1750. Print.

Connor, Francis X. "The Cambridge Edition of the Works of Ben Jonson Online and the Utility of the Digital Edition." Papers of the Bibliographical Society of America 109.2 (2015): 247-63. Print.

Cotgrave, Randle. A Dictionarie of the French and English Tongres. London, 1611. Print.

Davis, Robin Camille. "Taking Care of Digital Efforts: A Multiplanar View of Project Afterlives." 130th MLA Annual Convention. Vancouver, BC. 10 Jan. 2015. Conference Presentation.

Dawson, Giles E. "An Early List of Elizabethan Plays.” The Library 4th ser. 15.4 (1935): 445-56. Print.

Delius, Nicolaus, ed. Pseudo-Shakspere'sche Dramen. Vol. 5. Fair Em: ein Shakspere zugeschriebenes Drama. Elberfeld: Friderichs, 1874. Print.

Digital Renaissance Editions. Coord. Ed. Brett D. Hirsch. Digital Renaissance Editions. U of Victoria and Internet Shakespeare Editions, 2006-. Web. 15 Dec. 2015.

Drakakis, John, ed. The Merchant of Venice. London: Arden Shakespeare, 2010. Print.

Early Modern OCR Project (eMOP). PI: Laura Mandell. Initiatives for Digital Humanities, Media, and Culture, Texas A\&M U. 2012-. Early Modern OCR Project. Web. 15 Dec. 2015.

Edwards, Philip, ed. The Spanish Tragedy. London: Methuen, 1959. Print.

Elze, Karl. "Nachträgliche Bemerkungen zu 'Mucedorus' und 'Fair Em." Jabrbuch der Deutschen Shakespeare-Gesellschaft 15 (1880): 339-52. Print.

- Notes on Elizabethan Dramatists with Conjectural Emendations of the Text. 1st series. Halle: Max Niemeyer, 1880. Print.

- Notes on Elizabethan Dramatists with Conjectural Emendations of the Text. 2nd Series. Halle: Max Niemeyer, 1884. Print.

Fair Em. Dir. Tom DuMoniter. Perf. Matt Gieseke, Raeanna Martin-Hayden, Liv Reis, Nichole Scheele, and Jenny Zwigard. American Shakespeare Center 2014 Theatre Camp, Session 1. Blackfriars Playhouse, Staunton, VA. 13 July 2014. Performance. 
Fair Em. Dir. Margaret Capo. Oxford Ensemble of Shakespearean Artists. Tarbutton Theater, Oxford College, Emory University, Oxford, GA. 21-22 Nov. 2013. Performance.

Fair Em. Dir. Phil Willmott. Perf. Robert Donald, Tom Gordon-Gill, Madeline Gould, Caroline Haines, and Jack Taylor. The Steam Industry. Union Theatre, Southwark, London. 8 Jan. 2013. Performance.

Farmer, John S., ed. Fair Em. London: Tudor Facsimile Texts, 1911. Print.

Galey, Alan. "Mechanick Exercises: The Question of Technical Competence in Digital Scholarly Editing." Electronic Publishing: Politics and Pragmatics. Ed. Gabriel Egan. Tempe: Medieval and Renaissance Texts and Studies, 2010. 73-93. Print.

- "Signal to Noise: Designing a Digital Edition of The Taming of a Shrew." College Literature 36.1 (2009): 40-66. Print.

- The Shakespearean Archive: Experiments in New Media from the Renaissance to Postmodernity. Cambridge: Cambridge UP, 2014. Print.

Giddens, Eugene. "Digital Revolutions and Digital Delays: Electronic Editions of Renaissance Literature.” Book 2.0 1.1 (2011): 21-30. Print.

Gitelman, Lisa. Always Already New: Media, History, and the Data of Culture. Cambridge: MIT P, 2006. Print.

Greg, W. W., ed. Fair Em. Oxford: Oxford UP for the Malone Society, 1927. Print.

Henning, Standish, ed. Faire Em: An Introduction and Critical Edition. Diss. Harvard U, 1960. Print.

- ed. Fair Em. New York: Garland Publishing, 1980. Print.

Hirsch, Brett D. "The Kingdom has been Digitized: Electronic Editions of Renaissance Drama and the Long Shadows of Shakespeare and Print." Literature Compass 8.9 (2011): 568-91. Print.

Hirsch, Brett D., and Hugh Craig. "'Mingled Yarn': The State of Computing in Shakespeare 2.0.” The Shakespearean International Yearbook 14 (2014): 3-35. Print.

Hirsch, Brett D., and Kevin Quarmby, ed. Fair Em. Digital Renaissance Editions. Digital Renaissance Editions, 2015-. Web. 15 Dec. 2015.

Hopkinson, A. F., ed. Fair Em. London: M. E. Simms \& Co., 1895. Print.

Jackson, MacDonald P. "New Research on the Dramatic Canon of Thomas Kyd.” Research Opportunities in Medieval and Renaissance Drama 47 (2008): 107-27. Print.

Juxta. Computer software. Juxta: Collation Software for Scholars. Vers. 1.7.0. Applied Research in Patacriticism, U of Virginia, 2006-. Web. 20 Dec. 2015.

Kershaw, N. F. Theme and Presentation in the Native Romantic Comedy of the First Period of the Elizabethan Public Theatre (1576-1592), Together with an Old Spelling Edition of 'Fair Em', a Representative Play. Diss. U of York, 1972. Print.

Kirschenbaum, Matthew G., ed. Done. Spec. cluster of Digital Humanities Quarterly 3.2 (2009). Web. 15 Dec. 2015. 
Kirwan, Peter. "The First Collected 'Shakespeare Apocrypha." Shakespeare Quarterly 62.4 (2011): 594-601. Print.

- Shakespeare and the Idea of Apocrypha: Negotiating the Boundaries of the Dramatic Canon. Cambridge: Cambridge UP, 2015. Print.

Kozlenko, William, ed. The Disputed Plays of William Shakespeare. New York: Hawthorn, 1974. Print.

Lancashire, Anne, and Jill Levenson. "Anonymous Plays." The Predecessors of Shakespeare: A Survey and Bibliography of Recent Studies in English Renaissance Drama. Ed. Terence P. Logan and Denzell S. Smith. Lincoln: U of Nebraska P, 1973. 161-311. Print.

Lost Plays Database. Ed. Roslyn L. Knutson, David McInnis, and Matthew Steggle. Lost Plays Database. U of Melbourne, 2009-. Web. 15 Dec. 2015.

Mahood, M. M. Playing Bit Parts in Shakespeare. London: Routledge, c.1992. Print.

Manley, Lawrence, and Sally-Beth MacLean. Lord Strange's Men and Their Plays. New Haven: Yale UP, 2014. Print.

MLA Committee on Information Technology. "Statement on Electronic Publication." Modern Language Association. Modern Language Association, Oct. 2014. Web. 15 Dec. 2015.

Neville, Sarah. "Mediating Textual Annotation in the Online Scholarly Edition." The Shakespearean International Yearbook 14 (2014): 133-42. Print.

- Rev. of Fair Em, dir. Phil Willmott. Shakespeare Bulletin 31.3 (2013): 535-38. Print.

Osborne, Laurie E. The Trick of Singularity: 'Twelfth Night' and the Performance Editions. Iowa City: U of Iowa P, 1996. Print.

Performing the Queen's Men. Dir. Alexandra Johnston and Helen Ostovich. Shakespeare and the Queen's Men, Queen's Men Editions. McMaster U, and U of Toronto. 2006-07. The Queen's Men. Web. 15 Dec. 2015.

Pierazzo, Elena. "A Rationale of Digital Documentary Editions." Literary and Linguistic Computing 26.4 (2011): 463-77. Print.

A Pleasant Commodie, of faire Em. London, 1592-3? Print.

A Pleasant Comedie of Faire Em. London, 1631. Print.

Queen's Men Editions. Gen. Ed. Helen Ostovich. Queen's Men Editions. McMaster U, U of Toronto, and Internet Shakespeare Editions, 2006-. Web. 15 Dec. 2015.

Richard Brome Online. Gen. Ed. Richard Allen Cave. Richard Brome Online. Royal Holloway, $U$ of London, and the Humanities Research Institute, $U$ of Sheffield, 2010. Web. 15 Dec. 2015.

Roberts-Smith, Jennifer, Shawn DeSouza-Coelho, Teresa Dobson, Sandra Gabriele, Omar Rodriguez-Arenas, Stan Ruecker, Stéfan Sinclair, and Paul Stoesser with Alexandra Kovacs. "SET Free: Breaking the Rules in a Processual, User-Generated, Digital Performance Edition of Richard the Third." The Shakespearean International Yearbook 14 (2014): 69-99. Print. 
Schafer, Elizabeth. "Performance Editions, Editing and Editors." Shakespeare Survey 59 (2006): 198-212. Print.

Schoenbaum, Samuel. Internal Evidence and Elizabethan Dramatic Authorship. Evanston: Northwestern UP, 1966. Print.

Simpson, Richard, ed. The School of Shakspere. 2 vols. London: Chatto \& Windus, 1878. Print.

Simulated Environment for Theatre (SET). Computer software. Simulated Environment for Theatre. Vers. 12.12c. SET Research Team, U of Alberta, U of British Columbia, McMaster U, York U, and the U of Waterloo, 2009-. Web. 20 Dec. 2015.

Taylor, Gary. "The Renaissance and the End of Editing." Palimpsest: Editorial Theory in the Humanities. Ed. George Bornstein and Ralph G. Williams. Ann Arbor: U of Michigan P, 1993. 121-49. Print.

Tompkins, Joanne. "Making the Invisible Visible: Virtual Stage Props and Christopher Marlowe's Dr Faustus.” Performing Objects and Theatrical Things. Ed. Marlis Schweitzer and Joanne Zerdy. New York: Palgrave Macmillan, 2014. 161-72. Print.

Tyrrell, Henry, ed. The Doubtful Plays of William Shakspere. London: J. Tallis \& Co., 1853. Print.

VARD2. Computer software. VARD. Vers. 2.5.4. Alistair Baron, Lancaster U, 2008-. Web. 20 Dec. 2015.

Vickers, Brian. "Thomas Kyd, Secret Sharer." Times Literary Supplement Apr. 18 2008: 13-15. Print.

Warnke, Karl, and Ludwig Proescholdt, ed. Pseudo-Shakespearian Plays. Vol. 1. The Comedie of Faire Em. Halle: Max Niemeyer, 1883. Print.

Werstine, Paul. "Modern Editions and Historical Collation in Old-Spelling Editions of Shakespeare." Analytical and Enumerative Bibliography 4 (1980): 95-106. Print.

Willmott, Phil. Fair Em. London: Samuel French, 2013. Print.

Worthen, W. B. "The Imprint of Performance." Theorizing Practice: Redefining Theatre History. Ed. W. B. Worthen and Peter Holland. New York: Palgrave, 2003. 213-34. Print. 